fied and shown to be useful in well-defined contexts. Intending authors could do little better than study Prof. Spalding's exemplary model. Starting from a wealth of scholarship and experience, he has provided a lucid and logically developed exposition of a topic that can now almost be regarded as a discipline in its own right. A generous number of worked examples and a profusion of diagrams further enhance the value of this work, which is singularly free from the errors, omissions, ambiguities and inelegancies that characterize most text-books published to-day.

J. R. A. Pearson

\section{PETROLOGICAL MINERALOGY}

\section{Rock-forming Minerals}

By Prof. W. A. Deer, Dr. R. A. Howie and Dr. J. Zussman. Vol. 2: Chain Silicates. Pp. $x+379$. Vol. 3: Sheet Silicates. Pp. $x+270$. Vol. 4: Framework Silicates. Pp. $x+435$. Vol. 5: Non-Silicates. Pp. ix + 371. (London: Longmans, Green and Co., Ltd., 1962-63.) 95s. each volume.

7 HE first volume of this series was reviewed in Nature of July 7, 1962, p. 4. The work is now complete in four further volumes of similar average length of about 350 pages. Variations of chemical composition within a group, discussed on a structural basis, are treated throughout as fully as in Volume 1. The descriptions of the pyroxene group and of the amphibole group, for example, each occupy a little less than one-half of volume 2, and each account is accompanied by more than 200 selected analyses (there are more than 1,600 in the whole work), with optical data where available and the appropriate structural recalculations of numbers of ions. The account of each species concludes with a valuable discussion of the paragenesis.

It is difficult to find fault with the selections of references to recent work appended to the accounts of each species. References are stated to be comprehensive to 1959 (in Volume 4 to 1960), but there are many later additions-from Volume 4 one can trace stishovite, and recent work on melanophlogite, through references dated 1962. References are also given to selected classical papers, and here one sometimes misses a favourite; there seems to be no reference, for example, to Wahl's work on pyroxenes. A similar problem of selection has faced the authors in the matter of obsolescent mineral names. In Volume 2 there are indexed references to names such as magnophorite, osannite, and imerinite, though they are discarded as unnecessary; one cannot, however, trace damourite, gilbertite, or margarodite through Volume 3. Among preferred spellings are piemontite, katophorite, and felspar.

I have noticed even fewer printer's errors in these volumes than in Volume 1. This strengthens confidence in the accuracy of reproduction of the whole mass of numerical data, which can, of course, only be checked in detail by use. The index 110 is misplaced in Fig. $24 b$ of Volume 4, and the indexing of the figure of barytes is not in accordance with the structural description. It is not clear what is implied by the assertion, in the tabular statement of properties, that the orthorhombic pyroxenes show 'simple and lamellar' twinning on $\{100\}$, though there is, of course, a discussion of the significance of the lamellar structures later in the toxt. Fassaite is characterized, surely, by the strong development of the form $\{110\}$, and not of the zone [110]. Structurally it is improbable that periclase shows an octahedral cleavage though the statement is repeated in many text-books.

Inevitably, the speed with which mineralogical research is progressing means that some passages in these volumes already call for modification-the phase diagrams of Figs. 15 and 17 of Volume 2, for example, in the light of work published since 1960. One hopes that the make-up in five reasonably sized volumes (which are a delight to handle) will enable the authors more easily to keep pace with the revised editions which will surely be dernanded. This sub-division will also enable individuals to avoid the expense of the whole series, variously described by reviewers of Volume 1 in terms ranging from "rather expensive" to "lamentable", by acquiring only the volumes with which they are directly concerned. It seems likely that Volumes 2 and 4 will be most consulted, closely followed by Volume 1. Specialized literature already exists in the field of the clay-minerals and their allies, covered in the last third of Volume 3, and also for a number of the groups of non-silicates in Volume 5 , such as the opaque ores. In the remainder of the series, however, covering major mineral groups for which no comprehensive literature has hitherto been available, the authors have gone far beyond mere compilation and provide accounts which are informative and critical. There is no general index to the five volumes; this is little drawback to tracing mineral descriptions in view of the clear-cut division of the first four volumes on the basis of structural types, but it does sometimes make it less easy to locate more general matter such as references to a particular system.

Reviewing the work as a whole, one is left with a feeling of gratitude to the three authors for undertaking this very necessary but highly onerous task, and with nothing but admiration of the successful way in which they have carried it out. Just as one has automatically turned to 'Dana' for crystallographic data, and to 'Winchell' for optical data over the whole field of minerals, so 'Deer, Howie, and Zussman' will certainly establish itself as the standard source of information on the chemical, structural, and optical properties of the important rock-forming minerals.

F. C. Philurps

\section{DIAMONDS IN INDUSTRY}

\section{Proceedings of the First International Congress on} Diamonds in Industry

Held at the Centre des Conférences Internationales, Paris, 28 May-2 June, 1962. Pp. xi +407. (London: Industrial Diamond Information Bureau, 1963.) n.p.

7 HIS handsome volume of 400 quarto pages provides a valuable permanent record of papers read and discussed at the first International Congress on Diamonds in Industry, which was opened in Paris on Monday, May 28,1962 , and closed on the following Saturday. No fewer than 38 quite important papers were presented at the Congress, and in most cases were followed by a lively discussion. The inclusion of a report of these discussions in the symposium adds considerably not only to its scientific and technological but also to its human interest.

Diamond is, of course, of outstanding importance as a gemstone and (because of its extreme hardness) as an industrial material, but it is also of very special interest in solid-state physics on account of its unique behaviour and the (largely unpredictable) variations in its behaviour. Although its elementary composition has been realized for centuries and its crystal structure was one of the first (1913) to be established by the methods of X-ray crystal analysis, this was far from meaning that our knowledge of the mineral was complote. The discovery that, based on differences in thoir absorptive properties. diamonds can be classified into two 'types' was describod by Robertson, Fox and Martin (1931) in a famous paper and served as a signal for further research. In succoeding decades the interrelation of absorption and fluorescence, the alterations brought about by various forms of irradiation, the 'counting' and semi-conductive properties of certain specimens, and the first repeatable and large-scale production of diamond by artificial means, have oll acted as 